\title{
An Investigation on the Effect of Rail Corrugation on Track Response
}

\author{
Mohammad Fesharaki \\ Department of Civil and Environmental Engineering \\ Florida International University \\ 10555 West Flagler Street, Miami, USA
}

\begin{abstract}
Rail corrugation increases life cycle cost of both track and vehicle and is one of the main reasons of track and vehicle defects. To address this problem, this paper explores the effect of rail corrugation on track response. A Finite Element model developed to consider vehicle and track characteristics. Vehicle is a 10 degree of freedom mass-spring-dashpot model which can simulate vertical displacements and rotations. Rail is modeled as an Euler-Bernoulli beam with two degrees of freedom at each node which lies on discrete support to simulate sleeper and fastening system support. The total train-track matrices of mass, damping and stiffness have been formed. Solving the differential equations of motion in time domain for each time step results the response of track to train dynamic forces. A sensitivity analysis has been performed to explore the effect of different train and track parameters on rail displacement. The results of analyses show the effect of corrugation depth and wavelength as well as train speed and axle load on rail deflections and demonstrate the importance of each parameter in the studied range.
\end{abstract}

Keywords: Vehicle, track, corrugation, rail displacement, train speed

\section{INTRODUCTION}

Corrugation is major source of dynamic forces applied from vehicles. Based on AREMA (American Railway Engineering Maintenance of way Association), Corrugation initiates from rail head de-carbonization and irregularities such as; rail manufacture pitting, contact fatigue defects, rail welds, rail joints, etc. [1] Train axle load and speed are also important factors creating corrugation with specific wavelengths. Corrugation can be characterized by its depth and wavelength. Different depth and frequency can be detected in the field. UIC (International Union of Railways) divided corrugation into two categories: short-pitch corrugation with wavelength between 3 to $8 \mathrm{~cm}$ and long-pitch corrugation with wave length between 8 to $30 \mathrm{~cm} \mathrm{[2].}$

The importance of corrugation made many researchers to study this phenomenon to investigate causes, characteristics and treatment of corrugation. These studies, delved into different aspects of rail corrugation both theoretically and experimentally to consider the effect of different track types, vehicle condition, curvature and wheel-rail interaction [3].

Grassie reviewed different type of corrugation and proposed treatments. The effect of vehicle, rail type and traffic were also investigated[4].

Hempelmann and Knothe using an advanced linear model and based on assuming a feedback between structural dynamics and wear explained the formation of short pitch corrugation [5].

Egana et al conducted a research to study the influence of rail pad stiffness on rail corrugation. They concluded that soft rail pads can decrease the growth of corrugation and also eliminate one of the wavelengths [6].

Correa et al taking into account the dynamics of the track, the wheelset and the wear mechanism, developed a numerical method and investigated the effect of track radius on corrugation for four types of ballasted and ballastless high speed tracks [7]

Although the above mentioned papers and some other researches successfully addressed some important aspects of rail corrugation, the great influence of this rail flaw on deteriorating track and damaging wheels makes more research necessary. The aim of this paper is to investigate the effect of different parameters of corrugation and train on rail displacement using a numerical solution. The numerical method includes modeling of vehicle and track in time domain. The investigated parameters are, corrugation depth and wavelength, train speed and axle load. The purpose is to find the maximum response of track to each parameters in order to control the effective factors on corrugation and prioritize the maintenance activities. The results of the study can be used from freight to high-speed trains.

\section{MODELING PROCEDURE}

Although it is shown that the combination of physical and numerical modeling provide better results compared to numerical analysis in engineering application, [8], [9], [10] however numerical modeling considering realistic values may lead to good results. This is especially valid for a complicated problem of rail dynamic analysis. In this research a finite element model has been developed to consider the effect of rail corrugation on track response. The model consists of vehicle, track and their interactions. As 0 shows, the vehicle is a ten degree of freedom (DOF) mass spring damper model including a car body, two bogie frames and four wheel-sets. The car body has a mass of $M_{c}$ and a rotational moment of $j_{c}$ about the transverse horizontal axis. Bogies have mass of $m_{t}$ and rotational moment of $j_{t}$. Wheels are characterized by a mass of $m_{w}$ and have one DOF. It is assumed that the mass of each part is concentrated in the centroid of the tack components. the mass, stiffness and damping matrices of train can be expressed as follows: [11], [12] 


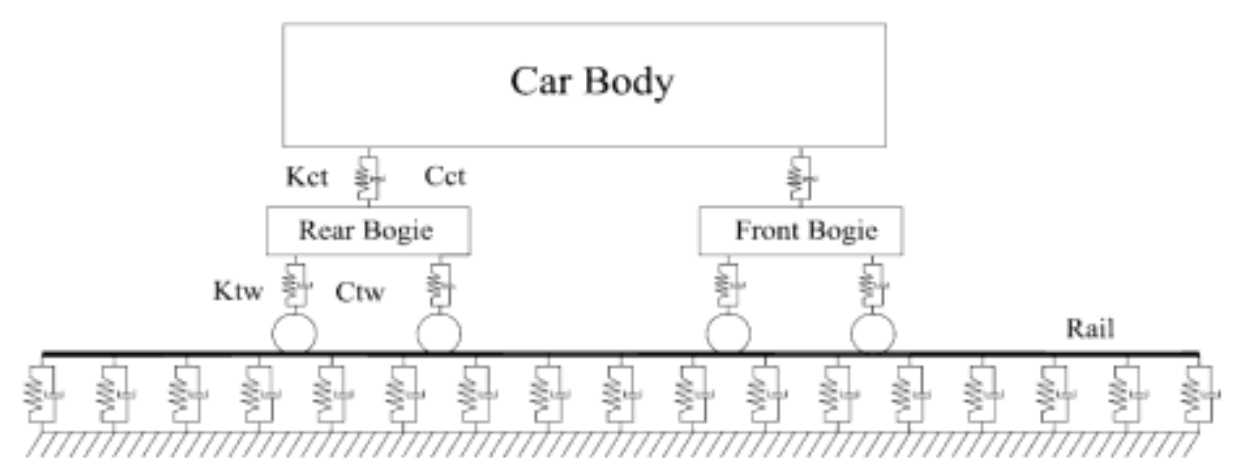

Figure.1 Vehicle and track model

$[\mathbf{M}]_{v}=\operatorname{diag}\left[\begin{array}{llllllllll}\mathrm{m}_{\mathrm{c}} & \mathrm{j}_{\mathrm{c}} & \mathrm{m}_{\mathrm{t}} & \mathrm{j}_{\mathrm{t}} & \mathrm{m}_{\mathrm{t}} & \mathrm{j}_{\mathrm{t}} & \mathrm{m}_{\mathrm{w} 1} & \mathrm{~m}_{\mathrm{w} 2} & \mathrm{~m}_{\mathrm{w} 3} & \mathrm{~m}_{\mathrm{w} 4}\end{array}\right]$ (1)

$[\mathbf{K}]_{\mathrm{v}}=\left[\begin{array}{cccccccccc}2 \mathrm{k}_{\mathrm{t}} & 0 & -\mathrm{k}_{\mathrm{t}} & 0 & -\mathrm{k}_{\mathrm{t}} & 0 & 0 & 0 & 0 & 0 \\ 0 & 2 \mathrm{k}_{\mathrm{t}} \mathrm{L}_{\mathrm{c}}^{2} & -\mathrm{k}_{\mathrm{t}} \mathrm{L}_{\mathrm{c}} & 0 & -\mathrm{k}_{\mathrm{t}} \mathrm{L}_{\mathrm{c}} & 0 & 0 & 0 & 0 & 0 \\ -\mathrm{k}_{\mathrm{t}} & -\mathrm{k}_{\mathrm{t}} \mathrm{L}_{\mathrm{c}} & \mathrm{k}_{\mathrm{t}}+2 \mathrm{k}_{\mathrm{w}} & 0 & 0 & 0 & -\mathrm{k}_{\mathrm{w}} & -\mathrm{k}_{\mathrm{w}} & 0 & 0 \\ 0 & 0 & 0 & 2 \mathrm{k}_{\mathrm{w}} \mathrm{L}_{\mathrm{t}}^{2} & 0 & 0 & -\mathrm{k}_{\mathrm{w}} \mathrm{L}_{\mathrm{t}} & -\mathrm{k}_{\mathrm{w}} \mathrm{L}_{\mathrm{t}} & 0 & 0 \\ -\mathrm{k}_{\mathrm{t}} & -\mathrm{k}_{\mathrm{t}} \mathrm{L}_{\mathrm{c}} & 0 & 0 & \mathrm{k}_{\mathrm{t}}+2 \mathrm{k}_{\mathrm{w}} & 0 & 0 & 0 & -\mathrm{k}_{\mathrm{w}} & -\mathrm{k}_{\mathrm{w}} \\ 0 & 0 & 0 & 0 & 0 & 2 \mathrm{k}_{\mathrm{w}} \mathrm{L}_{\mathrm{t}}^{2} & 0 & 0 & -\mathrm{k}_{\mathrm{w}} \mathrm{L}_{\mathrm{t}} & -\mathrm{k}_{\mathrm{w}} \mathrm{L}_{\mathrm{t}} \\ 0 & 0 & -\mathrm{k}_{\mathrm{w}} & -\mathrm{k}_{\mathrm{w}} \mathrm{L}_{\mathrm{t}} & 0 & 0 & \mathrm{k}_{\mathrm{w}} & 0 & 0 & 0 \\ 0 & 0 & -\mathrm{k}_{\mathrm{w}} & -\mathrm{k}_{\mathrm{w}} \mathrm{L}_{\mathrm{t}} & 0 & 0 & 0 & \mathrm{k}_{\mathrm{w}} & 0 & 0 \\ 0 & 0 & 0 & 0 & -\mathrm{k}_{\mathrm{w}} & -\mathrm{k}_{\mathrm{w}} \mathrm{L}_{\mathrm{t}} & 0 & 0 & \mathrm{k}_{\mathrm{w}} & 0 \\ 0 & 0 & 0 & 0 & -\mathrm{k}_{\mathrm{w}} & -\mathrm{k}_{\mathrm{w}} \mathrm{L}_{\mathrm{t}} & 0 & 0 & 0 & \mathrm{k}_{\mathrm{w}}\end{array}\right]$

(2)

$[\mathbf{C}]_{v}=\left[\begin{array}{cccccccccc}2 c_{t} & 0 & -c_{t} & 0 & -c_{t} & 0 & 0 & 0 & 0 & 0 \\ 0 & 2 c_{t} L_{c}{ }^{2} & -c_{t} L_{c} & 0 & -c_{t} L_{c} & 0 & 0 & 0 & 0 & 0 \\ -c_{t} & -c_{t} L_{c} & c_{t}+2 k_{w} & 0 & 0 & 0 & -c_{w} & -c_{w} & 0 & 0 \\ 0 & 0 & 0 & 2 c_{w} L_{t}^{2} & 0 & 0 & -c_{w} L_{t} & -c_{w} L_{t} & 0 & 0 \\ -c_{t} & -c_{t} L_{c} & 0 & 0 & c_{t}+2 c_{w} & 0 & 0 & 0 & -c_{w} & -c_{w} \\ 0 & 0 & 0 & 0 & 0 & 2 c_{w} L_{t}^{2} & 0 & 0 & -c_{w} L_{t} & -c_{w} L_{t} \\ 0 & 0 & -c_{w} & -c_{w} L_{t} & 0 & 0 & c_{w} & 0 & 0 & 0 \\ 0 & 0 & -c_{w} & -c_{w} L_{t} & 0 & 0 & 0 & c_{w} & 0 & 0 \\ 0 & 0 & 0 & 0 & -c_{w} & -c_{w} L_{t} & 0 & 0 & c_{w} & 0 \\ 0 & 0 & 0 & 0 & -c_{w} & -c_{w} L_{t} & 0 & 0 & 0 & c_{w}\end{array}\right]$

(3)

In equations (1) to (3), $\mathrm{L}_{\mathrm{c}}$ is half of the distance between two bogies and $\mathrm{L}_{\mathrm{t}}$ is the half of the distance between two wheels of the same bogie. $\mathrm{K}_{\mathrm{t}}, \mathrm{K}_{\mathrm{tw}}, \mathrm{C}_{\mathrm{t}}$ and $\mathrm{C}_{\mathrm{tw}}$ denote stiffness and damping of the secondary and primary suspension system of the vehicle respectively. $\mathrm{K}_{\mathrm{w}}$ and $\mathrm{C}_{\mathrm{w}}$ are the spring and damping constants between the rail and vehicle. 0 show the parameters and the assigned values in numerical analysis.

Table 1. Rail vehicle properties

\begin{tabular}{lc}
\hline \multicolumn{1}{c}{ Parameter } & Value \\
\hline Mass of car body $(\mathrm{kg})$ & 49500 \\
Car body inertia moment $\left(\mathrm{kg} . \mathrm{m}^{2}\right)$ & $2.15 \times 10^{6}$ \\
Mass of bogie $(\mathrm{kg})$ & 3200 \\
bogie inertia moment $\left(\mathrm{kg} . \mathrm{m}^{2}\right)$ & 4000 \\
Distance between bogie centers $(\mathrm{m})$ & 12.5 \\
Mass of wheel axle $(\mathrm{kg})$ & 900 \\
Secondary suspension stiffness $(\mathrm{N} / \mathrm{m})$ & $1.74 \times 10^{5}$ \\
Secondary suspension damping $(\mathrm{N} . \mathrm{s} / \mathrm{m})$ & $4.50 \times 10^{4}$ \\
Primary suspension stiffness $(\mathrm{N} / \mathrm{m})$ & $6.33 \times 10^{5}$ \\
Primary suspension damping $(\mathrm{N} . \mathrm{s} / \mathrm{m})$ & $4.08 \times 10^{4}$ \\
\hline
\end{tabular}

The track and its supporting layer were modeled as beam and discrete mass-less springs and viscous dampers. The springs represent the track sub-layers, connecting the beam to the subgrade. Neglecting axial deformations, each beam element has four DOF which can described by Cubic Hermitian shape functions. Therefore, displacements of the beam elements' nodes can be calculated by the following expression. [12], [13]

$$
y(e, t)=N(e) \times q_{i}(t)
$$

Where $y(e, t)$ is the vertical displacement of the rail element. $q_{i}(t)$ is the nodal displacement vector of rail and $\mathrm{N}(\mathrm{e})$ is the matrix of the beam shape functions as follows:

$$
N_{1}(e)=\left[\begin{array}{llll}
N_{1}(e) & N_{2}(e) & N_{3}(e) & N_{4}(e)
\end{array}\right]
$$

Where

$$
\begin{aligned}
& N_{1}(e)=1-\left(\frac{e}{l}\right)^{2}+2\left(\frac{e}{l}\right)^{3} \\
& N_{2}(e)=e\left[1-2\left(\frac{e}{l}\right)+2\left(\frac{e}{l}\right)^{2}\right] \\
& N_{3}(e)=3\left(\frac{e}{l}\right)^{2}-2\left(\frac{e}{l}\right)^{3} \\
& N_{4}(e)=e\left[\left(\frac{e}{l}\right)^{2}-\left(\frac{e}{l}\right)\right]
\end{aligned}
$$

In which "l" and "e" respectively demonstrate the length and local coordinate of the elements measured from the left node of elements. The mass and stiffness matrices of beam elements $\left(M_{r}\right.$ and $K_{r}$ ) can be written in the following form:

$$
\begin{aligned}
& {\left[M_{r}\right]=\frac{\bar{m} l}{420}\left[\begin{array}{cccc}
156 & 22 l & 54 & -13 l \\
22 l & 4 l^{2} & 13 l & -3 l^{2} \\
54 & 13 l & 156 & -22 l \\
-13 l & -3 l^{2} & -22 l & 4 l^{2}
\end{array}\right]} \\
& {\left[K_{r}\right]=\frac{E_{r} I_{r}}{l^{3}}\left[\begin{array}{cccc}
12 & 6 l & -12 & 6 l \\
6 l & 4 l^{2} & -6 l & 2 l^{2} \\
-12 & -6 l & 12 & -6 l \\
6 l & 2 l^{2} & -6 l & 4 l^{2}
\end{array}\right]}
\end{aligned}
$$

Where $\bar{m}, E_{r}$ and $I_{r}$ stand for the mass per unit length, the modulus of elasticity and the moment of inertia of beam elements, respectively.

Considering the mass, stiffness and damping matrices of the vehicle and track elements, the dynamic equation of the whole system can be presented in the following format.

$[M]\{\ddot{y}\}+[C]\{\dot{y}\}+[K]\{y\}=\{P(t)\}$ 
Where, $[\mathrm{M}],[\mathrm{C}]$, and $[\mathrm{K}]$ are the matrices representing mass, damping and the stiffness of train-track coupling system, respectively. $\{y\},\{\dot{y}\}$ and $\{\ddot{y}\}$ are displacement, velocity and acceleration of train-track elements, respectively. $\mathrm{P}(\mathrm{t})$ indicates the vector of load induced by the passage of the train. Table. 2 shows track parameters used in numerical analysis. Note that the length of beam elements is assumed to be $0.6 \mathrm{~m}$ which is the typical distance between cross ties. So the model has 80 elements and 81 nodes and consequently, the total number of DOFs for rail is 162 .

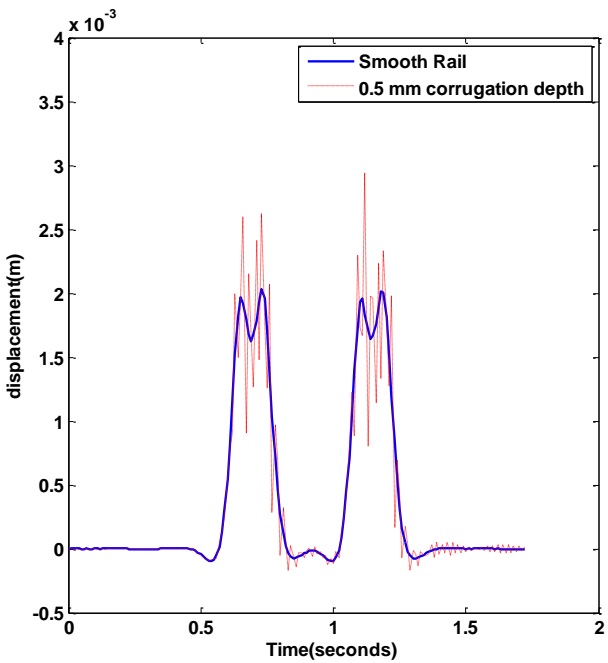

Table 2. Rail track properties

\begin{tabular}{lc}
\hline Parameter & Value \\
\hline Track length $(\mathrm{m})$ & 48 \\
Rail modulus of elasticity $\left(\mathrm{N} / \mathrm{m}^{2}\right)$ & $2 \times 10^{11}$ \\
Rail moment of inertia $\left(\mathrm{m}^{4}\right)$ & $2.34 \times 10^{-5}$ \\
Mass per unit length of rail $(\mathrm{Kg} / \mathrm{m})$ & 55 \\
Distance between sleepers $(\mathrm{m})$ & 0.6 \\
\hline
\end{tabular}

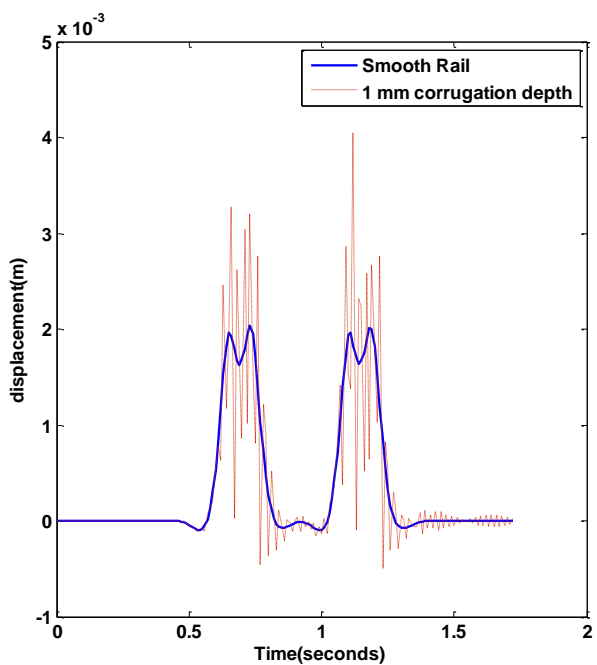

Figure. 2 Rail displacement for different rail corrugation depth (left) $0.5 \mathrm{~mm}$ (right) $1 \mathrm{~mm}$

\section{VEHICLE-TRACK SYSTEM}

Hertz contact theory is used to model the interaction between vehicle and track structure. Neglecting rail irregularities, the contact force between wheel and rail may be determined using Hertz theory through the following formula:[14]

$\mathrm{P}=\mathrm{K}_{\mathrm{H}}\left(y_{\text {wheel }}-y_{\text {raill }}\right)$

Where $\mathrm{K}_{\mathrm{H}}$ is linearized Hertzian spring constant which is a function of wheel and rail profile radius and their material properties.

To solve the dynamic equations of motion, Newmark integration method is used. This method developed by Newmark (1959) is based on the assumption that the acceleration varies linearly between two instants of time. The following formula can be applied

$$
\begin{aligned}
& \dot{u}_{i+1}=\dot{u}_{i}+[(1-\gamma) \Delta t] \ddot{u}_{i}+(\gamma \Delta t) \ddot{u}_{i+1} \\
& u_{i+1}=u_{i}+\dot{u}_{i} \Delta t+\left\lfloor(0.5-\beta)(\Delta t)^{2} \mid \ddot{u}_{i}+\left[\beta(\Delta t)^{2}\right] \ddot{u}_{i+1}\right.
\end{aligned}
$$

Where $\Delta t$ is time step, $\gamma$ and $\beta$ show the variation of acceleration during one time step. In the numerical solution, the values of $\gamma$ and $\beta$ are 0.5 and 0.25 , as a result, the solution will be unconditionally stable. Time step, $\Delta t$ is chosen 0.005 seconds. Applying equations 11 and 12, the track response at time " $\mathrm{t}+\mathrm{dt}$ " can be determined if response is known at time " $\mathrm{t}$ ". [13]

\section{RESULTS}

Error! Reference source not found. compares the result of analyses for a smooth track and corrugated track with different depth. The figure shows the rail displacement for 0.5 $\mathrm{mm}$ and $1 \mathrm{~mm}$ corrugation depth. The maximum displacement in perfect condition is $2 \mathrm{~mm}$. $0.5 \mathrm{~mm}$ deep corrugation increases the rail deflection to $3 \mathrm{~mm}$. 0 alsoError! Reference source not found. depicts the same results for $1 \mathrm{~mm}$ corrugation. As expected, rail displacement increases with increasing the depth of corrugation and the maximum difference between ideal and defected track displacement is about $100 \%$.

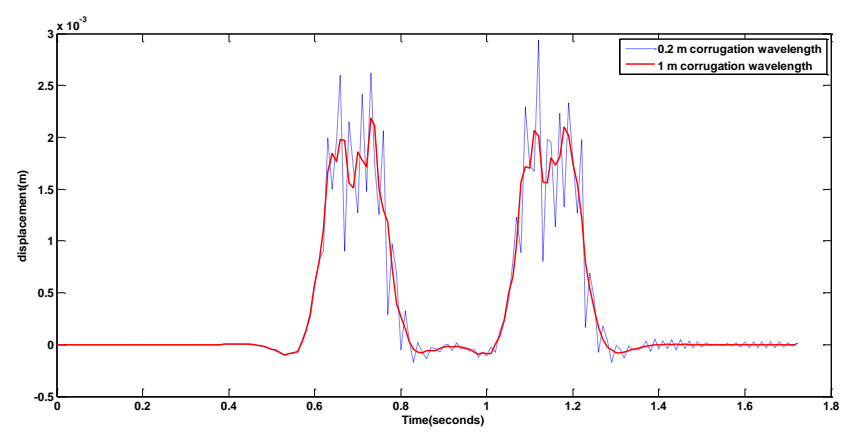

Figure. 3 The effect of corrugation wavelength on rail displacements

To investigate the impact of wavelength on rail response, the analyses are performed for wavelength of $0.2 \mathrm{~m}$ and $1 \mathrm{~m} .0$ demonstrates the effect of corrugation wavelength on rail deflection. Increasing corrugation wavelength causes a reduction in rail displacement. As the figure shows about $40 \%$ drop in rail displacement can be seen by increasing the wavelength.

Train axle load is an important parameter to raise rail displacement. This can be seen in 0 which shows the influence of train axle load on rail displacements. It should be noted that to obtain this graph, it is assumed that vehicle speed is $100 \mathrm{~km} / \mathrm{hr}$. and wavelength and depth of corrugation are 0.2 $\mathrm{m}$ and $0.5 \mathrm{~mm}$. The minimum displacement from the cases 
shown in 0 is $2.4 \mathrm{~mm}$ corresponding to 10 ton axle load. By increasing the train load, rail displacement increases and for
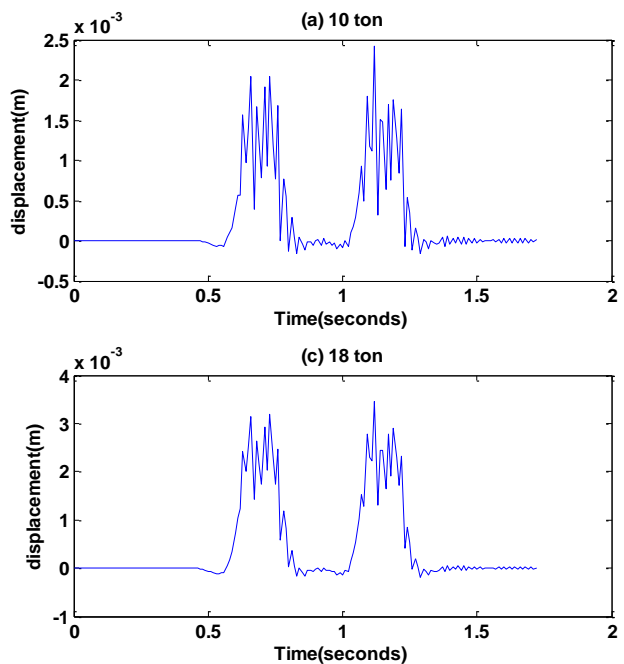

22 ton axle load reaches to $3.97 \mathrm{~mm}$.

Figure. 4 The effect of axle load on rail displacement
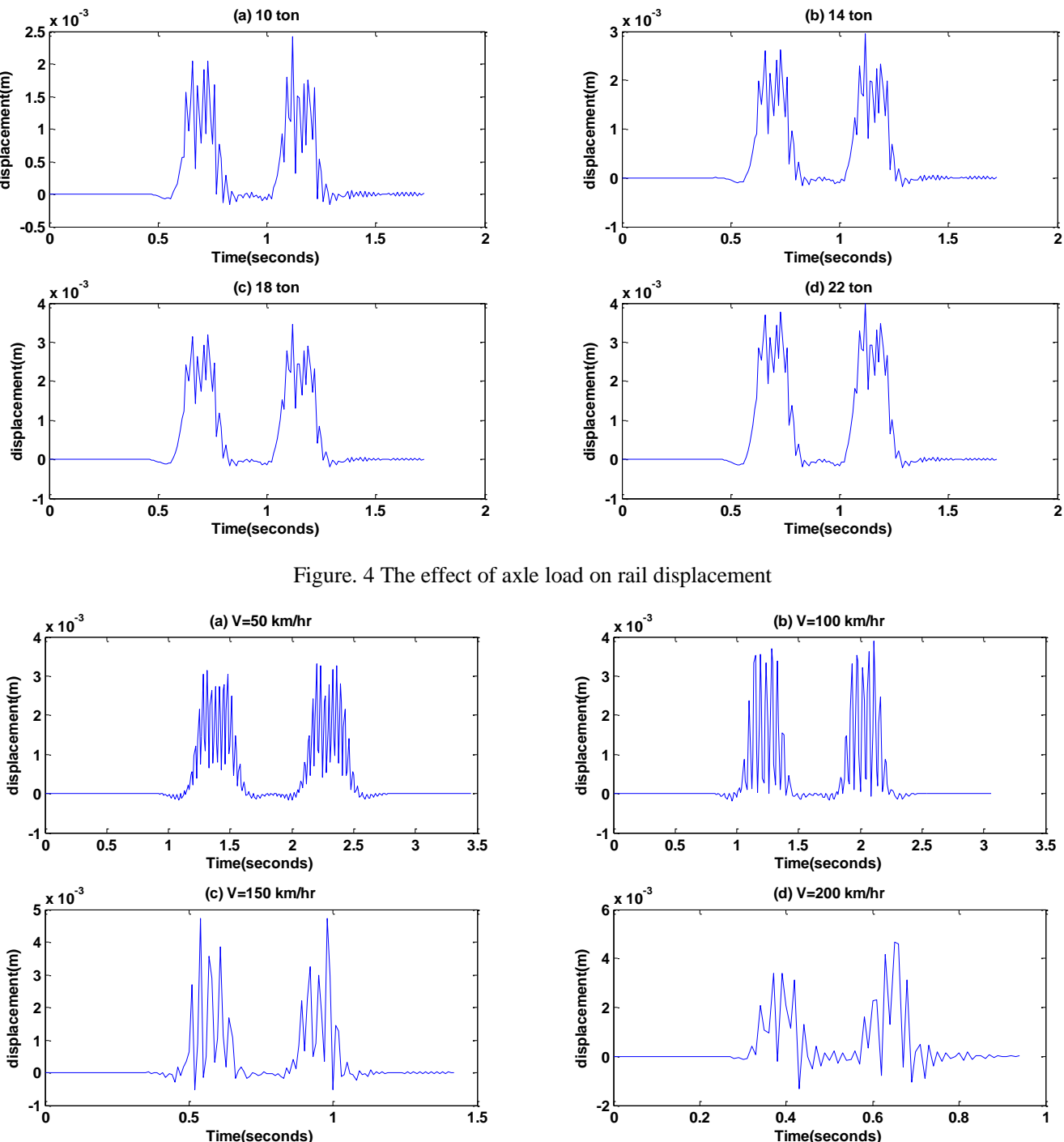

Figure. 5 The effect of train speed on rail displacements

In intercity lines, vehicles with different speeds may travel and the passage of trains with different speeds can create corrugation with varying depth and wavelength. As a result, train speed is one of the most influential parameters on rail response. In this part, it is assumed that axle load is 14 ton and corrugation parameters i.e. wavelength and depth are $0.2 \mathrm{~m}$ and $0.5 \mathrm{~mm}$ and constants. The results presented for speeds $50,100,150$ and $200 \mathrm{~km} / \mathrm{hr}$.

As 0 shows, the maximum rail displacement under loads moving at the speed of $50 \mathrm{~km} / \mathrm{hr}$ is $3.1 \mathrm{~mm}$. With increasing vehicle speed, rail displacement also increases and for speed $100 \mathrm{~km} / \mathrm{hr}$ reaches $3.8 \mathrm{~mm}$. This trend is valid for $150 \mathrm{~km} / \mathrm{hr}$. train speed and the maximum deflection raises to 4.7 and. Increasing the speed of vehicle more than this point results in a decrease in rail displacement. The maximum displacement for $200 \mathrm{~km} / \mathrm{hr}$ train speed is 4.6 . As a result, $150 \mathrm{~km} / \mathrm{hr}$ is the critical speed for this case. 0 illustrates the difference in critical speed with varying corrugation wavelength. An increase in corrugation wavelength results in increasing critical speed. So in case of high-speed train, long wavelength corrugation should be avoided.

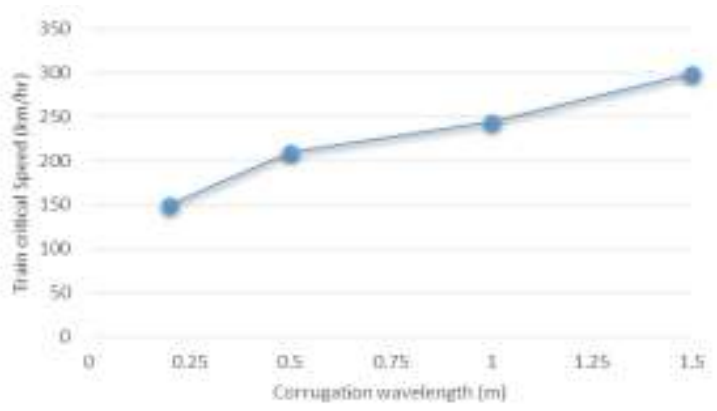

Figure. 6 The effect of corrugation wavelength on train critical speed

\section{CONCLUSIONS}

This paper explored the influence of corrugation on track displacement by using a finite element model of track and 
vehicle. Vehicle is simulated by mass-spring-damper model and rail is considered as Euler-Bernoulli beam and the whole system has been solved in time-domain by Newmark integration method. The results of the study show rail displacement under different conditions and determine the effect of train and track parameters on rail response. The results of the study can be summarized as follows

- Increasing corrugation depth results in about $40 \%$ increase in rail displacement. Wavelength have almost the same effect and changing wavelength causes $50 \%$ alternation in rail displacement

- The maximum effects of axle load and train speed in the considered range are $58 \%$ and $62 \%$ respectively.

- Corrugation is a very important factor in increasing dynamic effect of rail vehicles. This is very crucial in case of low wavelength and deep corrugation. Controlling of corrugation depth and wavelength is very important in case of freight and high-speed trains.

- Increasing train speed does not necessarily increases rail deflection. For each case of corrugation wavelength and depth, vehicle critical speed should be determined and considered for design purposes.

\section{REFERENCES}

[1] American Railway Engineering and Maintenance-ofWay Association, Manual for Railway Engineering, Vol.1, Track. 2010.

[2] International Union of Railways, "Rail defects, UIC code 712R," 2002.

[3] K. H. Oostermeijer, "Review on short pitch rail corrugation studies," Wear, vol. 265, no. 9-10, pp. 1231-1237, 2008.

[4] S. L. Grassie, "Rail corrugation: Characteristics, causes, and treatments," Proc. Inst. Mech. Eng. Part F J. Rail Rapid Transit, vol. 223, no. 6, pp. 581-596, 2009.

[5] K. Hempelmann and K. Knothe, "An extended linear model for the prediction of short pitch corrugation," Wear, vol. 191, no. 1-2, pp. 161-169, 1996.

[6] J. I. Egana, J. Vinolas, and M. Seco, "Investigation of the influence of rail pad stiffness on rail corrugation on a transit system," Wear, vol. 261, no. 2, pp. 216224, 2006.

[7] N. Correa, O. Oyarzabal, E. G. Vadillo, J. Santamaria, and J. Gomez, "Rail corrugation development in high speed lines," Wear, vol. 271, no. 9-10, pp. 2438-2447, 2011.

[8] A. Hamedi and H. R. Fuentes, "Comparative Effectiveness and Reliability of NEXRAD Data to Predict Outlet Hydrographs Using the GSSHA and HEC-HMS Hydrologic Models," in World Environmental and Water Resources Congress,
2015, no. September 2005, pp. 1444-1453.

[9] A. Hamedi and H. R. Fuentes, "New Relationship between a Vertical Gate Opening and Downstream Flow Stability: Experimental Development," World Environ. Water Resour. Congr. 2016, pp. 47-57, 2016.

[10] M. Baqersad, A. E. Haghighat, M. Rowshanzamir, and H. M. Bak, "Comparison of Coupled and Uncoupled Consolidation Equations Using Finite Element Method in Plane-Strain Condition," Civ. Eng. J., vol. 2, no. 8, pp. 375-388, 2016.

[11] X. Lei and N. A. Noda, "Analyses of Dynamic Response of Vehicle and Track Coupling System With Random Irregularity of Track Vertical Profile," vol. 258, no. May, pp. 147-165, 2002.

[12] P. Lou and Q. Zeng, "Formulation of equations of motion of finite element form for vehicle-trackbridge interaction system with two types of vehicle model," Int. J. Numer. Methods Eng., vol. 62, no. 3, pp. 435-474, 2005.

[13] A. K. Chopra, Dynamics of Structures, 4th ed. Prentice-Hall, 2011.

[14] C. Esveld, Modern Railway Track, 2nd ed. MRT Publications, 2001. 